\title{
SISTEM PENDUKUNG KEPUTUSAN PENGAKTIFAN FITUR 4G LTE PADA BTS MENGGUNAKAN METODE PROMETHEE BERBASIS WEB
}

\author{
I Komang Yogi Sutrisna ${ }^{1}$, Made Sudarma ${ }^{2}$, Putu Arya Mertasana ${ }^{3}$ \\ 1,2,3 Jurusan Teknik Elektro, Fakultas Teknik, Universitas Udayana \\ Email : sutrisna1093@gmail.com ${ }^{1}, \underline{\text { msudarma@unud.ac.id }}{ }^{2}, \underline{\text { mertasna@ee.unud.ac.id }}{ }^{3}$
}

\begin{abstract}
Abstrak
Kemajuan teknologi informasi dan telekomunikasi yang begitu pesat telah mendorong semakin berkembangnya sebuah informasi. Salah satunya informasi mengenai persaingan yang ketat dalam melakukan alternatif pengembangan jaringan akses. Dipilinnya jaringan 4G dimaksudkan sebagai solusi jaringan komunikasi yang komprehensif dan aman, dengan kecepatan data yang jauh lebih cepat dari generasi sebelumnya. Secara umum hal tersebut diminta untuk menyediakan layanan berkualitas tinggi dan kecepatan transfer data yang lebih cepat. Perencanaan suatu sistem yang dapat membantu dalam pemilihan BTS untuk diaktifkan fitur $4 G$ sangat diperlukan oleh operator jaringan telekomunikasi dalam menentukan BTS yang sesuai dengan kriteria yang diinginkan. Pada penelitian ini telah dapat dibuat sebuah SPK (Sistem Pendukung Keputusan) berbasis web untuk menyelesaikan masalah alternatif pemilihan BTS. Pengembangan dari aplikasi yang dibangun ini menggunakan metodologi Waterfall System. Sedangkan metode pengambilan keputusan menggunakan metode Preference Ranking Organization Method for Enrichment Evaluation (PROMETHEE). Pada tahap implementasi, sistem ini menggunakan bahasa pemrograman PHP, serta MySQL sebagai databasenya. Sistem pendukung keputusan ini dapat menghasilkan alternatif BTS yang disarankan sesuai dengan kriteria yang didasarkan pada hasil analisis metode PROMETHEE. Perbedaan dari 2 jenis perhitungan secara manual dan menggunakan sistem terlihat pada peringkat 3 terbaik dari 20 BTS yang diseleksi.
\end{abstract}

Kata Kunci : Sistem Pendukung Keputusan, BTS Fitur 4G, Metode PROMETHEE

\begin{abstract}
Rapid development in information technology and telecommunications has encouraged the development of information. One of them is information about the intense competition in the development of alternative access networks. $4 G$ network is intended as a solution for communications network which considered comprehensive and secure, with data speeds much faster than the previous generation. In general it is asked to provide high quality service and faster data transfer speeds. Planning a system which can assist in the selection of BTS for indispensable 4G feature is enable telecommunications network operators in determining which BTS that is suitable for the desired criteria. This research can be made a DSS (Decision Support System) web-based to solve the problem of the selection of alternatives BTS. Development of the applications built using Waterfall methodology System. While for method of decision-making is used Preference Ranking Organization Method for Enrichment Evaluation (PROMETHEE). In the implementation stages, the system uses the PHP programming language and MySQL as the database. Decision support systems can produce alternatives BTS that suggested according to criteria based on the results of analysis methods PROMETHEE. Differences of two types of manual calculation and use the system shown at the three best ranked of 20 base stations were selected.
\end{abstract}

Keywords: Decision Support System, BTS feature 4G, PROMETHEE Method

1. PENDAHULUAN

I Komang Yogi Sutrisna, Made Sudarma, Putu Arya Mertasana
Seiring perkembangan ilmu pengetahuan di dunia saat ini, mendorong berkembangnya 
teknologi informasi dan telekomunikasi. Di dalam era persaingan yang ketat, rencana dalam jangka panjang tidak lagi menarik karena tuntutan supply dan demand selalu bergeser dalam periode yang cepat. PT. XL Axiata selaku operator jaringan telekomunikasi dihadapkan untuk selalu dapat mengambil keputusan yang cepat dalam melakukan alternatif pengembangan jaringan akses. Jaringan 4G LTE adalah jaringan nirkabel generasi keempat untuk telekomunikasi mobile. Jaringan ini dimaksudkan sebagai solusi jaringan komunikasi yang komprehensif dan aman dengan kecepatan data yang jauh lebih cepat dari generasi sebelumnya. Jaringan 4G secara spesifik diarahkan untuk menyediakan layanan dan kecepatan transfer yang cepat dan tinggi.

Pengambilan keputusan adalah proses pemilihan dari berbagai alternatif yang bertujuan untuk memenuhi satu atau beberapa sasaran. Sistem pengambilan keputusan memiliki 4 fase, yaitu intelligence, design, choice, dan implementation. Salah satu sistem dari metode pengambilan keputusan adalah $P R O$ METHEE (Preference Rangking Organizational Method for Enrichment Evaluation). Metode PROMETHEE adalah suatu metode penentuan prioritas dalam analisa masalah pokoknya adalah kesederhanaan, kejelasan, dan kestabilan. Sistem pendukung keputusan diperlukan dalam permasalahan pemilihan BTS (Base Tower Station) yang tepat, metode PROMETHEE adalah salah satu metode yang dipergunakan dalam penelitian ini karena metode ini cukup baik dalam memperhitungkan karakteristik dari data yang didapat.

Adanya sistem ini diharapkan dapat membantu operator provider telekomunikasi dalam mendukung pengambilan keputusan untuk mengaktifkan 4G LTE pada BTS yang sudah terpasang.

\section{KAJIAN PUSTAKA}

\subsection{Pengertian Sistem}

Suatu sistem adalah suatu jaringan kerja dari prosedur-prosedur yang saling berhubungan, berkumpul untuk saling berhubungan, terkumpul menjadi satu untuk melakukan suatu kegiatan atau untuk menyelesaikan suatu sasaran tertentu[1].

Sistem mempunyai Karakteristik atau sifat-sifat tertentu, yaitu :

a. Komponen-komponen sistem

b. Batasan sistem

c. Lingkungan luar sistem d. Penghubung sistem

e. Masukan sistem

f. Pengolahan sistem

g. Keluaran sistem

h. Sasaran sistem

\subsection{Keputusan}

Keputusan merupakan aktivitas atau tindakan yang diambil sebagai solusi dari suatu permasalahan[2]. Untuk menghasilkan keputusan yang baik ada beberapa tahapan proses yang harus dilalui dalam pengambilan keputusan. Proses pengambilan keputusan melalui beberapa tahap diantaranya :
a. Tahap penelusuran
b. Tahap desain
c. Tahap pemilihan
d. Tahap implementasi

\subsection{Sistem Pendukung Keputusan (SPK)}

SPK dapat didefinisikan sebagai model dari sekumpulan prosedur yang digunakan untuk melakukan pengolahan data dengan tujuan agar dapat membantu manajer dalam pembuatan keputusan yang sifatnya spesifik[3]. Penerapan SPK hanya akan berhasil jika sistem bersifat sederhana, mudah untuk digunakan, mudah dalam melakukan pengawasan, mudah beradaptasi dengan perubahan lingkungan serta mudah berkomunikasi dengan jenis entity yang lain.

\subsection{Preference Ranking Organization Me- thod for Enrichment Evaluation (PRO- METHEE) \\ PROMETHEE adalah suatu metode pe-} nentuan urutan (prioritas) dalam analisis multikriteria. Masalah pokoknya adalah kesederhanaan, kejelasan, dan kestabilan. Dugaan dari dominasi kriteria yang digunakan dalam PROMETHEE adalah penggunaan nilai dalam hubungan outrangking. Semua parameter yang dinyatakan mempunyai pengaruh nyata menurut pandangan ekonomi. Secara metode PROMETHEE perhitungan dilakukan melalui Persamaan (1) :

$$
\begin{array}{ll}
H(d) \quad\left\{\begin{array}{l}
\text { d/p Jika }-p \leq d \leq p \\
1 \text { Jika } d<-p \text { atau } d>p
\end{array}\right.
\end{array}
$$

$$
\begin{aligned}
& \text { Keterangan : } \\
& \quad d \text { adalah Nilai kriteria } \\
& H(d) \text { adalah selisih nilai kriteria }
\end{aligned}
$$


p adalah preferensi BTS a terhadap BTS

b

Tabel 1. Pehitungan Mencari Bobot

\begin{tabular}{|l|c|c|c|c|c|c|c|}
\hline \multicolumn{1}{|c|}{ Kriteria } & Data & Data 3.5G & Subscriber & Paket Data & Traffic & Lokasi & $\begin{array}{c}\text { Priority } \\
\text { Vector }\end{array}$ \\
\hline Data & 1 & 2 & 3 & 4 & 5 & 6 & $\mathbf{0 , 3 8}$ \\
\hline Data 3.5G & 0,5 & 1 & 2 & 3 & 4 & 5 & $\mathbf{0 , 2 5}$ \\
\hline Subscriber & 0,33 & 0,5 & 1 & 2 & 3 & 4 & $\mathbf{0 , 1 6}$ \\
\hline Paket Data & 0,25 & 0,33 & 0,5 & 1 & 2 & 3 & $\mathbf{0 , 1}$ \\
\hline Traffic & 0,2 & 0,25 & 0,33 & 0,5 & 1 & 2 & $\mathbf{0 , 0 7}$ \\
\hline Lokasi & 0,17 & 0,2 & 0,25 & 0,33 & 0,5 & 1 & $\mathbf{0 , 0 5}$ \\
\hline Jumlah & $\mathbf{2 , 4 5}$ & $\mathbf{4 , 2 8}$ & $\mathbf{7 , 0 8}$ & $\mathbf{1 0 , 8 3}$ & $\mathbf{1 5 , 5}$ & $\mathbf{2 1}$ & \\
\hline
\end{tabular}

\subsection{Bobot}

Bobot merupakan nilai yang ditentukan untuk mengetahui kriteria mana yang paling diutamakan dari setiap kriteria. Cara mencari bobot dapat dilihat pada Tabel 1 :

\subsection{Kriteria}

Kriteria merupakan sebuah parameter atau syarat-syarat yang diperlukan dalam menentukan dan memutuskan untuk menetapkan suatu keputusan. Penelitian ini menggunakan beberapa kriteria sebagai berikut :

a. Data

Data adalah deskripsi dari sesuatu dan kejadian yang kita hadapi

b. Data 3.5G

Data 3.5G adalah teknologi transmisi data pita lebar yang dapat digunakan secara berpindah-pindah yang berbasis HSDPA (High-Speed Downlink Package Access)

c. Traffic

Traffic adalah perpindahan informasi dari satu tempat ke tempat lain melalui jaringan telekomunikasi

d. Coverage

Coverage adalah cakupan atau jangkauan dari layanan selular, baik voice maupun data dari operator.

e. Lokasi

Lokasi adalah tempat dimana suatu aktivitas telekomunikasi dilakukan.

f. Mobilitas

Mobilitas adalah gerak perubahan atau perpindahan komunikasi dr tempat yang satu ke tempat yang lain

\subsection{XAMPP}

$X A M P P$ adalah software grafis yang di tujukan pada pengguna Windows Operating
System. Walaupun dalam versi linux telah ada software ini, namun dalam pengoperasiannya mengunakan perintah text. Hal ini mengakibatkan menjalankan software ini dalam linux sedikit sulit dibandingkan dengan windows. Namun kelebihan software ini jika di jalankan pada linux lebih lancar di banding dengan windows. Software yang merupakan software web server apache yang di dalamnya sudah terdapat database seperti mysql, php dan masih banyak lagi.

\subsection{MySQL}

MySQL adalah sebuah system manajemen database relasi (relational database management system) yang bersifat open source. Terbuka maksudnya adalah MySQL boleh di download oleh siapa saja, baik versi binernya (executable program) dan bisa digunakan secara (relatif) grafis baik untuk dimodifikasi sesuai dengan kebutuhan seseorang maupun sebagai suatu program aplikasi komputer[6]. MySQL memiliki kinerja, kecepatan proses dan ketangguhan yang tidak kalah dibanding database-database besar lainnya yang komersil seperti Oracle, Sybase, Unify dan sebagainya.

\subsection{PHP}

PHP adalah bahasa pemrograman script server-side yang didesain untuk pengembangan web. Selain itu, PHP juga bisa digunakan sebagai bahasa pemrograman umum. PHP di kembangkan pada tahun 1995 oleh Rasmus Lerdorf, dan sekarang dikelola oleh The PHP Group[5]. PHP disebut bahasa pemrograman server side karena PHP diproses pada komputer server. Hal ini berbeda dibandingkan dengan bahasa pemrograman client-side seperti 
Tabel 2. Daftar BTS dan Nilai Kiteria Pada Program SPK

\begin{tabular}{|c|c|c|c|c|c|c|c|}
\hline $\begin{array}{c}\text { Id } \\
\text { BTS }\end{array}$ & Nama BTS & $\begin{array}{c}\text { Data } \\
\text { (Pack) }\end{array}$ & $\begin{array}{l}\text { Data } \\
\text { 3.5G }\end{array}$ & $\begin{array}{l}\text { Traffic } \\
\text { (Data) }\end{array}$ & $\begin{array}{c}\text { Coverage } \\
\text { (Meter) }\end{array}$ & $\begin{array}{l}\text { Lokasi } \\
\text { (Orang) }\end{array}$ & $\begin{array}{c}\text { Mobilitas } \\
(\% / \%)\end{array}$ \\
\hline 1 & $\begin{array}{l}\text { BTS Puri } \\
\text { Maharani }\end{array}$ & 11798 & 11323 & 4575 & 25 & 1303 & 50 \\
\hline 2 & $\begin{array}{l}\text { BTS Sukum Bali } \\
\text { Cottages }\end{array}$ & 12880 & 11100 & 6700 & 25 & 989 & 50 \\
\hline 3 & BTS Quest San & 11765 & 11561 & 5746 & 10 & 1311 & 100 \\
\hline 4 & $\begin{array}{l}\text { BTS Inna Bali } \\
\text { Heritage }\end{array}$ & 13421 & 11009 & 4459 & 25 & 1980 & 50 \\
\hline 5 & $\begin{array}{l}\text { BTS Bali Dream } \\
\text { Costel }\end{array}$ & 13901 & 12300 & 3873 & 50 & 1705 & 100 \\
\hline 6 & BTS Sunda Hotel & 14879 & 11301 & 2577 & 10 & 1939 & 100 \\
\hline 7 & $\begin{array}{l}\text { BTS Abian } \\
\text { Residance }\end{array}$ & 16088 & 12091 & 1704 & 10 & 839 & 100 \\
\hline 8 & $\begin{array}{l}\text { BTS Dee } \\
\text { Mansion }\end{array}$ & 12567 & 11501 & 2506 & 10 & 1793 & 50 \\
\hline 9 & BTS Red Doorz & 14124 & 10390 & 3465 & 50 & 1501 & 50 \\
\hline 10 & $\begin{array}{l}\text { BTS Taman Suci } \\
\text { Suite }\end{array}$ & 15109 & 10351 & 4577 & 25 & 1231 & 50 \\
\hline 11 & BTS Pondok Sari & 12868 & 11500 & 4756 & 25 & 1081 & 100 \\
\hline 12 & $\begin{array}{l}\text { BTS The } \\
\text { Rha dana Kuta }\end{array}$ & 15787 & 10531 & 6506 & 50 & 899 & 100 \\
\hline 13 & BTS Green Villas & 11986 & 11260 & 5564 & 25 & 1180 & 50 \\
\hline 14 & BTS Dayu Beach & 13805 & 11320 & 4069 & 10 & 1803 & 100 \\
\hline 15 & $\begin{array}{l}\text { BTS Astana } \\
\text { Kunti }\end{array}$ & 11511 & 11476 & 3647 & 25 & 1033 & 50 \\
\hline 16 & $\begin{array}{l}\text { BTS Fivelements } \\
\text { Puri }\end{array}$ & 14119 & 12009 & 2937 & 10 & 1339 & 100 \\
\hline 17 & BTS Sandi Phala & 15749 & 11998 & 1705 & 50 & 938 & 50 \\
\hline $1 \mathrm{~s}$ & BTS Max One & 12789 & 11335 & 2457 & 50 & 1903 & 100 \\
\hline 19 & BTS Grand Zuri & 11620 & 11270 & 3774 & 25 & 1030 & 100 \\
\hline 20 & $\begin{array}{l}\text { BTS Grandmas } \\
\text { Plus }\end{array}$ & 11862 & 11206 & 4485 & 10 & 1308 & 50 \\
\hline
\end{tabular}

JavaScript yang diproses pada web browser (client).

\section{METODE PENELITIAN}

\subsection{Lokasi dan Waktu Penelitian}

Penelitian yang penulis lakukan mengenai sistem pendukung keputusan, bertempat di kantor PT. XL Axiata dan kantor vendor pemasangan BTS yang bekerjasama dengan PT. XL Axiata. Waktu penelitian dilaksanakan sewaktu-waktu mengikuti kesepakatan dengan petugas lapangan penyedia data.

\subsection{Tahap Penelitian}

Penelitian yang baik dan terarah akan menghasilkan kesimpulan yang baik pula. Agar penelitian berjalan dengan baik dan terarah maka diperlukan kerangka penelitian didalamnya yang berisi suatu deskripsi dari langkah-langkah yang harus dilakukan dalam melakukan penelitian yaitu :

a. Pengumpulan Materi

b. Analisa dan Perancangan Sistem

c. Implementasi

d. Pengujian

e. Pembuatan Laporan

Proses yang dapat dilakukan user dengan hak akses sebagai admin secara detail yaitu melakukan proses pengaturan dan penyimpanan data yang menyangkut aplikasi sistem pendukung keputusan tersebut. Pengujian dilakukan menggunakan 20 BTS yang akan diseleksi dan menetapkan ranking pada BTS yang nantinya akan diaktifkan fitur $4 G$ LTE.

Setiap BTS telah memiliki masing-masing 6 nilai kriteria. Nilai dari masing-masing kriteria tersebut lalu diinputkan kedalam menu input data kriteria, seperti pada Tabel 2.

Setelah semua BTS dan nilai kriteria masing-masing diinputkan, sistem secara otomatis akan melakukan penghitungan untuk menentukan BTS yang menempati ranking tertinggi.

\section{Hasil dan Pembahasan}

\subsection{Hasil Aplikasi}

Penelitian dalam skripsi ini menghasilkan sebuah aplikasi sistem pendukung keputusan dengan metode PROMETHEE berbasis WEB. Aplikasi WEB ini yang dibangun menggunakan bahasa pemrograman PHP, serta untuk menyimpan data mempergunakan database MySQL. Hasil perangkingan dapat dilihat pada menu analisa. Urutan rangking yang ditetapkan oleh sistem sesuai dengan jumlah nilai kri- 


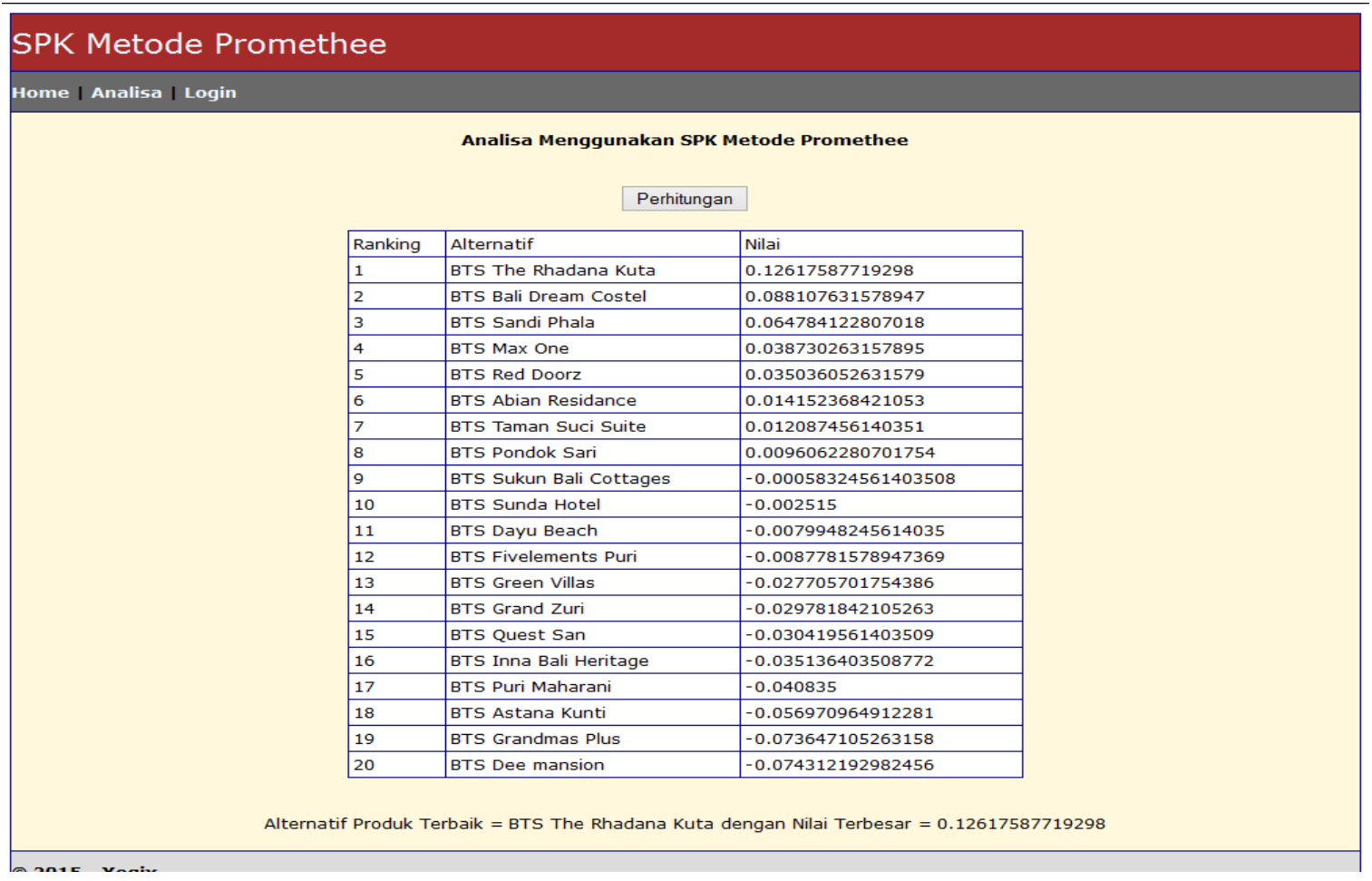

kriteria. Hasil perangkingan danat dilihat nada Tabel 3.

Tabel 3. Hasil Analisa Perhitungan

\subsection{Implementasi Aplikasi Berbasis WEB}

Tampilan aplikasi sistem pendukung keputusan pengaktifan fitur 4G LTE pada website yang dapat diakses secara online. Kode program merupakan bagian dari sebuah program yang berguna untuk menjalankan sistem pendukung keputusan.

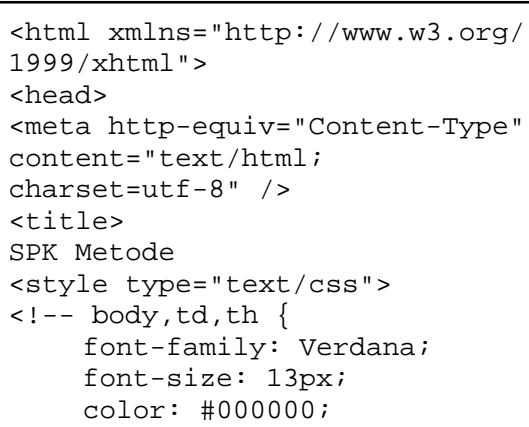

Kode Program 1. Kode Program Tampilan Halaman Admin

\subsection{Realisasi Perancangan}

min vana hanva dapat diakses oleh pengguna gan PROMETHEE sebagai admin. Halaman aIlalısa uala aurnin tersebut mencakup menu BTS, Kriteria, BTS Kriteria, History dan Ganti Password. Halam admin dapat dilihat pada Gambar 1.

\section{KESIMPULAN DAN SARAN \\ 5.1 Kesimpulan}

Adapun kesimpulan setelah merancang dan membuat sistem pendukung keputusan pengaktifan fitur 4G LTE pada BTS menggunakan metode PROMETHEE berbasis WEB

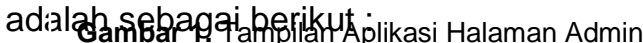

a. Sistem pendukung keputusan pengaktifan fitur 4G LTE pada BTS menggunakan metode PROMETHEE berbasis WEB telah berhasil dibangun dan dapat digunakan.

b. Perbandingan hasil dari perangkingan BTS menggunakan Sistem Pendukung Keputusan dengan metode PROMETHEE dengan perhitungan secara manual mendapatkan hasil yang berbeda :

\section{Komang Yogi Sutrisna, Made Sudarma, Putu Arya Meı}

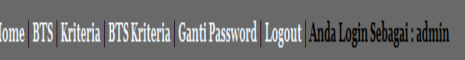


- Pada perhitungan dengan menggunakan metode PROMETHEE hasil perangkingan yang diperoleh menunjukan 3 alternatif $B T S$ terbaik yaitu rangking pertama BTS The Radhana Kuta, kedua BTS Bali Dream Costel, dan ketiga BTS Sandi Phala.

- Sedangkan jika menggunakan perhitungan secara manual hasil perangkingan menunjukan 3 alternatif BTS terbaik yaitu rangking pertama $B T S$ The Radhana Kuta, kedua BTS Bali Dream Costel, dan ketiga BTS Sukun Bali Cottages.

Perbedaan dari 2 jenis perhitungan tersebut terlihat pada alternatif $B T S$ peringkat 3 terbaik dari 20 BTS yang diseleksi. Maka oleh sebab itu diperlukan sistem pendukung keputusan ini untuk mendapatkan hasil yang lebih akurat dibandingkan dengan cara perhitungan secara manual yang hanya menjumlahkan nilai-nilai kriteria dari setiap BTS.

\subsection{Saran}

Adapun saran untuk pengembangan lebih lanjut sistem ini adalah sebagai berikut

a. Sistem ini dapat ditambahkan dengan metode yang lain seperti metode AHP (Analytical Hierarcy Process) untuk memperoleh perbandingan hasil yang lebih akurat.

b. Menambahkan jumlah kriteria dan indikator lain untuk dijadikan perbandingan dan hasil yang lebih baik.

6. DAFTAR PUSTAKA

[1] Jogiyanto, 2005. Analisis dan Desain Sistem Informasi, Penerbit Andi Offset, Yogyakarta.

[2] Turban, 2005. Decision Support Systems and Inteligent Systems. Andi Offset, Yogyakarta.

[3] Wahyu, 2014. "Sistem Pendukung Keputusan Kelayakan Pemberian Kredit Motor Menggunakan Metod SAW Pada Perusahaan Leasing HD Finance" (Jurnal Tugas Akhir). UniversitasDian Nuswantoro Semarang.

[4] Arbie, 2004. Manajemen Database dengan MySQL. Andi , Yogyakarta.

[5] Dewi, 2009. Sistem Pendukung Keputusan Menggunakan Metode AHP dan TOPSIS. 